\title{
How to Advance the Cognition Practice of Undergraduates Majoring in Functional Materials at the Professional Direction of Biomedical Textile Materials and Technology Based on the Textiles Science?
}

\author{
Jing Gao, Baozhong Sun, Jing Lin, Yan Li, Lu Wang \\ College of Textiles, Donghua University, Shanghai, China \\ Email: gao2001jing@dhu.edu.cn
}

How to cite this paper: Gao, J., Sun, B.Z., Lin, J., Li, Y., \& Wang, L. (2020). How to Advance the Cognition Practice of Undergraduates Majoring in Functional Materials at the Professional Direction of Biomedical Textile Materials and Technology Based on the Textiles Science? Open Journal of Social Sciences, 8, 217-222.

https://doi.org/10.4236/jss.2020.83019

Received: November 28, 2019

Accepted: March 17, 2020

Published: March 20, 2020

\begin{abstract}
This paper expounds the necessity, existing problems and improvement forms of cognition practice of undergraduates majoring in functional materials at the professional direction of biomedical textile materials and technology, in the College of Textiles of Donghua University. Through the carding of practice process, the innovation of practice assessment form, and the analysis of the key factors affecting the practice effect, the innovative exploration of advanced teaching form is carried out in order to achieve the significant improvement of the practice teaching effect.
\end{abstract}

\section{Keywords}

Cognition Practice, Biomedical Textile Materials and Technology,

Undergraduate

\section{Introduction}

Functional materials specialty of Donghua University is constructed as the national characteristic specialty and corresponds to the national emerging strategic industries, supported by the Ministry of Education in China. It relies on the special disciplines of textile, materials and chemical biology, and has three professional directions of biomedical textile materials and technologies, biomaterials, new energy and optoelectronic materials. Among them, the biomedical textile materials and technology is based on the textile science which is the national 
"double first-class" discipline. This major direction pays attention to the multidisciplinary fusion of biology, medicine and textile functional materials through learning the basic theories and knowledge about biological basis, medical basis, textile medical materials and biomedical textiles preparation. The courses study enable the undergraduates to acquire basic scientific training in biomedical textile materials and technology, engineering design capabilities, new product development capabilities, basic training in trade and organizational management capabilities, and understand the latest developments in related disciplines, familiar with the scientific research, technology development, functional design and marketing of biomedical textiles. Finally, the undergraduates can engage in research, development, production, teaching, management and trade in the fields of medical textiles, artificial organs, biofunctional materials, health care textiles etc.

In order to strengthen students' practical ability and innovative spirit, the cognition practice is considered as the antecedent course for students before other professional courses. This course enables students to have a thorough understanding of the major development prospects, innovative skills, learning content and work background, and helps students to establish a preliminary concept of functional materials, and then stimulate students' interest and motivation in learning courses. On the basis of the original cognition practice, we explore new teaching mode of professional cognition practice. First, we adopt either professional leaders at school, senior engineers of enterprises, or heads of school-enterprise projects as lecturers, and establish more comprehensive-process off-campus practice bases in related industries. After the internship, we organize expert forum to discuss the innovate mechanism and follow-up development of the enterprise products to strengthen students' understanding of the relevance among the cross-disciplinary subject groups. In addition, we also optimize the course content and assessment methods to obtain a satisfactory course effect.

\section{Existing Problems of Traditional Cognition Practice}

\subsection{Insufficient Mobilization and Preparation for Cognition Practice}

Generally, there are not full-time teachers with the cognition practice, which is conducted in only 1 - 2 weeks. It is not enough to fully mobilize and emphasize importance of cognition practice to the students in the early stage of the practice. Also the supervision and management during the cognition practice is not effective, which would reduce the practice effects.

\subsection{Lack of Professional Teacher Team for Cognition Practice}

Most of the young teachers currently employed in the university graduate from either " 985 " or " 211 " universities and are with doctoral qualifications. Relatively speaking, they are not have much experience in contact with production. Be- 
sides, due to the interdisciplinary characteristics of functional materials specialty, the professional teachers have different academic backgrounds. So the focus content of the lectures during the practice will be different due to the difference of the teacher's academic background. The teaching effect cannot be assessed with advantage.

\subsection{Single Form and İncomplete Course Evaluation of Cognition Practice}

At present, most of the cognition practices are visiting enterprises. Students incline more passive acceptance and less active participation. Therefore, the students' enthusiasm to learn is not enough which lead to glance over processes hurriedly and sloppy. Besides, the employment direction of the graduates is diversified with the development of economic diversification. Some students would like to work non professional work after graduation. So they are not interested in the practice enterprises; or they think the practice is just to understand simply or go through the motions.

In addition, traditional cognitive practice is mostly evaluated in written form such as attendance assessment and practice reports. It is difficult for the instructors to understand the students' mastery of the internship content and production site timely, and it is also impossible to evaluate the effect of the internship visually and accurately.

\section{Exploration and Innovation of the Form of Cognition Practice}

\subsection{Improve the Practice Management Mechanism}

In view of the problems of insufficient mobilization and preparation in the early stage of practice, the main solutions are as follows. First, in terms of organization, the college leaders should attach great importance to the practice. The practice should be recognized as an important course for construction. Second, to establish a stable team of internship instructors, teams with excellent, experienced and responsible teachers and old, middle and young teachers should be constructed to ensure the teaching quality. At the same time, in view of the diversity of teachers' professional orientations, the combination of teachers from different professional backgrounds can make the teaching contents comprehensive and the students to achieve the professional knowledge without "dead corners". Third, the active mobilization work before the practice should be carried out to improve students' understanding of the internship, and let them realize that the internship is the first key link to combine the theoretical knowledge with the actual production, and the internship will play an important role in the future graduation internship, graduation project, and even the job (Vereijken, et al., 2019). The students should understand the cognition practice is not to skim the surface, but to "get into the heart" and "get into the brain." Mobilization before cognition practice should strengthen the students' self-discipline and pro- 
fessionalism, and consolidate students' understanding of their career planning and their majors.

\subsection{Construct the Practice Bases and Develop the Part-Time Teachers in the Enterprise}

At present, functional materials specialty based on the textile science are related to the formation of fiber materials, molding of textile structure, functional finishing of materials, design of engineering structure, biology, medicine, biochemistry, optoelectronics etc., which is with numerous and large span knowledge-modules and wide curriculum content. It is difficult for students to learn the knowledge systematically and modularize during the cognition practice. In response to this problem, the main solution is further to expand the extension of the internship bases, and pay more attention to the selection of the internship bases. Those enterprises with more industry influence, with more representative products, and with more mature producing processes should be as the primary selection criteria for our internship. In addition, we should improve the part-time teacher mechanism in these unique practice bases and develop senior engineers, heads of school-enterprise projects to serve as part-time practice teachers. All of them have rich practical experiences and are familiar with the on-site technological processes. Better combination between production and $\mathrm{R} \& \mathrm{D}$ will be provided to students by in-depth instruction, and cooperative spirit and team awareness also will be conveyed to the students.

\subsection{Cultivate Teams of Professional Teachers with Both "Innovative " and "Engineering"}

Due to the introduction of interdisciplinary talents, there are relatively few young teachers with profound understanding of production practice based on textile subject. Under such circumstances, the college or teaching departments should actively create conditions to culture young teachers to regularly exercise and learn to relative enterprises, and encourage young teachers to participate in school-enterprise cooperation projects. Parts of the enterprises are traditional production enterprises, which can provide good engineering support to improve young teachers' practical ability. Another part of the enterprises are innovative $\mathrm{R} \& \mathrm{D}$ enterprises, which can promote the transformation of research results and production and improve the collaborative innovation abilities of the teacher teams.

Secondly, the young teachers will cooperate with the experienced senior teachers during lead of the cognition practice to play the role of the college spirit of "impart-help-lead". Which can ensure the quality of the practice teaching, while cultivate the young teachers of good professional qualities.

\subsection{Reform the Content and Form of the Cognition Practice}

In addition to the enterprises visiting, we have actively explored to reform the 
existing internship content and form. First of all, in order to avoid the phenomenon that students just have a quick glance at the production enterprises, in the early stage of the internship, we would arrange students to watch to learn the sample machine operated by the experimental teachers in the college comprehensive training centre. Relying on the college of textiles of Donghua University, which is the earliest constructed key disciplines and of the right to confer degrees of bachelor, master and doctor. The college has a complete sample machines, test equipment and implementation platform for the entire production process of fiber material processing. Therefore, the students would have a preliminary understanding of the fiber materials processing and small quantitative trial production, combining with on-site Q\&A and discussion to deep the students' initial cognition of production equipment and process characteristics. They will have a better foundation in the later large-scale production learning, and understanding of the students' process routes and product goals.

Secondly, the cognition practice is not limited to the level of visits any more. Senior enterprise engineers can be invited to introduce and discuss with the students in advance, so that the students have comprehensive knowledge of the corporate history, production process, products advancement and applicability. Let the students have a clear acquaintance of the development history of the company, so that they can better understand the current situation of the company. In the process of introducing the company, the students are encouraged to actively ask questions and enhance the enthusiasm of the students through interaction.

\subsection{Innovative the Evaluation Mechanism of Cognition Practice}

The evaluation mechanism is an important means of teaching management to cognition practice. Also it is an important segment to promote the "first-class" undergraduate construction of functional materials specialty. Assessment and evaluation is a necessary means, which purpose is to establish a scientific and reasonable evaluation mechanism, and improve students' enthusiasm, and urge students to delve deeper in the process of the internship (Weir et al., 2019). At the same time, the instructors can keep abreast of the students' mastery of the internship content and then provide targeted guidance. Therefore, it is necessary to formulate a more scientific and reasonable evaluation system to ensure the practice effect.

In order to improve the evaluation method, more attention should be paid to the timely conduct by means of combining production on-site $\mathrm{Q} \& \mathrm{~A}$, internship visit with discussion, in order to supervise and guide students having a deep understanding of production practice.

In addition, since the practice is a concentrated internship, the content of the internship report tends to be too similar. It is difficult to assess the students' grades only by the internship diary and the internship report. Therefore, the evaluation method should also be combined with the internship examination 
and the multimedia report etc., which can make a fair and reasonable assessment of the students' entire internship process.

\section{Conclusion}

The cognition practice is arranged in the second semester, which is the initial stage for students majoring in functional materials to realize and understand the specialty profession. It is an essential segment to cultivate advanced engineering technology talents both application-oriented and innovative. The practice takes on the task of professional sensibility, course perceptual cognition, and professional cultural cognition, which will has a profound impact on students' future learning. The teaching methods, internship forms, and assessment standards of internships should be constantly explored and kept up with the times, all for the motives to make full use of the important cohesive role of cognitive internships both from theory to practice, and from practice to theory during the teaching process.

\section{Acknowledgements}

This work was supported by 2017 Teaching reform project for higher education of China National Textile and Apparel Council (No. 2017BKJGLX187); and 2019 University Course Navigation Plan in Shanghai.

\section{Conflicts of Interest}

The authors declare no conflicts of interest regarding the publication of this paper.

\section{References}

Vereijken, M. W. C., Van Der Rijst, R. M., Van Driel, J. H., \& Dekker, F. W. (2019). Authentic Research Practices throughout the Curriculum in Undergraduate Medical Education: Student Beliefs and Perceptions. Innovations in Education and Teaching International. https://doi.org/10.1080/14703297.2019.1674680

Weir Laura, K., Barker Megan, K., McDonnell Lisa, M., Schimpf Natalie, G., Rodela Tamara, M., \& Schulte Patricia, M. (2019) Small Changes, Big Gains: A Curriculum-Wide Study of Teaching Practices and Student Learning in Undergraduate Biology. PLoS ONE, 8, 57. https://doi.org/10.1371/journal.pone.0220900 